\title{
Inbalt des fünften Bandes (Teil II)
}

Fortgesetzte Nachricht von des Verfassers eignen Schrif-

ten, bis zum 1745sten Jahre. . . . . . . . . . 3

Der Ersten Gründe der Weltweisheit

Praktischer Theil.

Einleitung zur praktischen Weltweisheit ůberhaupt. . . 69

Der praktischen Weltweisheit Erster Theil.

Die allgemeine Sittenlehre.

Einleitung zur allgemeinen Sittenlehre. . . . . . . . 77

Das I. Hauptstůck.

Von den Handlungen der Menschen und ihrem Unterscheide. . . . . . . . . . . . . . . . 79

Das II. Hauptstůck.

Von dem Gesetze der Natur und der Verbindlichkeit desselben. .............. 86

Das III. Hauptstưcck.

Von der Tugend, und von dem Laster. . . . . . . . 96

Das IV. Hauptstůck.

Von der menschlichen Glúckseligkeit, und von den

Mitteln dazu zu gelangen. . . . . . . . . . . 104

Das V. Hauptstúck.

Von dem Gewissen, und der Beobachtung desselben. 120 
Das VI. Hauptstůck.

Von der Bekehrung eines Lasterhaften oder von der philosophischen Buße. . . . . . . . . . . . 131

Das VII. Hauptstůck.

Von der Kunst, sich selbst und andere zu prúfen, ob man tugendhaft oder lasterhaft sey? . . . . . . . 140 Das VIII. Hauptstůck.

Von der Beståndigkeit im Guten, und den Wachsthume in der Tugend. . . . . . . . . . . . . . . 149

Der praktischen Weltweisheit Zweyter Theil.

Das Recht der Natur.

Einleitung zum Rechte der Natur. . . . . . . . . . 159

Der erste Abschnitt.

Von den Pflichten eines jeden Menschen, im Zustande der natürlichen Gleichheit.

Das I. Hauptstůck.

Von den Pflichten gegen Gott. . . . . . . . . . 161

Das II. Hauptstůck.

Von den Pflichten des Menschen gegen sich selbst. 170 Das III. Hauptstůck.

Von den Pflichten gegen andere Menschen ůberhaupt. 184 Das IV. Hauptstůck.

Von den Pflichten in Worten und Vertrågen. . . . . 196 Das V. Hauptstůck.

Von den Pflichten im Absehen auf das Eigenthum. 207 Das VI. Hauptstůck.

Von den Vergleichen oder Contracten. . . . . . 216 
Des Rechtes der Natur

Zweyter Abschnitt.

Von den Pflichten eines rechtschaffenen Bůrgers.

Das I. Hauptstůck.

Von der Gesellschaft ůberhaupt. . . . . . . . . 231

Das II. Hauptstůck.

Von der ehelichen Gesellschaft. . . . . . . . . 235

Das III. Hauptstůck.

Von der văterlichen Gesellschaft. . . . . . . . . . . 242

Das IV. Hauptstůck.

Von der herrschaftlichen Gesellschaft. . . . . . . 249

Das V. Hauptstůck.

Von dem Hauswesen, oder von einer Familie. . . . 254

Das VI. Hauptstůck.

Von dem gemeinen Wesen, und dessen Einrichtung ùberhaupt. . . . . . . . . . . . . . . . 257

Das VII. Hauptstůck.

Von Stiftung eines Staates oder gemeinen Wesens. . . 262 Das VIII. Hauptstůck.

Von den bůrgerlichen Gesetzen. . . . . . . . . 272

Das IX. Hauptstůck.

Von der hôchsten Macht und Gewalt der Regenten. 277 Das X. Hauptstůck.

Von Verwaltung des gemeinen Wesens. . . . . 283

Das XI. Hauptstû́ck.

Vom Rechte des Krieges und Friedens. . . . . . . 288

Der praktischen Weltweisheit Dritter Theil.

Die Tugendlehre.

Einleitung zur Tugendlehre. . . . . . . . . . 295 
Der erste Abschnitt.

Von den Vorbereitungen zur Tugend.

Das I. Hauptstůck.

Von der Lust und Liebe zur Tugend. . . . . . . . . 299

Das II. Hauptstůck.

Von Verbesserung der ersten Kraft des Verstandes und der Erlangung der Schărfsinnigkeit und Tiefsinnigkeit. . . . . . . . . . . . 30s

Das III. Hauptstů́ck.

Von der Einsicht, Wissenschaft, und Grůndlichkeit. 312 Das IV. Hauptstůck.

Von dem Witze, der Kunst, und Geschicklichkeit im Erfinden. . . . . . . . . . . . . . . . . 319 Das V. Hauptstůck.

Von der Weisheit und Klugheit. . . . . . . . . . 328 Das VI. Hauptstůck.

Von Beherrschung der Gemůthsbewegungen. . . . 335

Der zweyte Abschnitt.

Von Erlangung der sittlichen Tugend.

Das I. Hauptstück.

Von der sittlichen Tugend ůberhaupt, und dem Erkenntnisse seiner selbst. . . . . . . . . . 345

Das II. Hauptstůck.

Von der Måßigkeit im Essen und Trinken. . . . . . 351

Das III. Hauptstůck.

Von der Sorgfalt für seinen Leib, und von der Keuschheit. . . . . . . . . . . . . . . . . 360

Das IV. Hauptstůck.

Von dem Fleiße, der Sparsamkeit und Freygebigkeit. 369 Das V. Hauptstúck.

Von der Bescheidenheit, der Demuth und dem Edelmuthe. 
Das VI. Hauptstůck.

Von der Standhaftigkeit, der Unerschrockenheit und Måßigung im Glücke. . . . . . . . . . . . . 393 Das VII. Hauptstůck.

Von der Menschenliebe, Sanftmuth und Freundschaft. 399 Das VIII. Hauptstúck.

Von der Aufrichtigkeit, Verschwiegenheit, und Gesprå̀chsamkeit. . . . . . . . . . . . . . . . 409 Das IX. Hauptstůck.

Von der Gerechtigkeit und Redlichkeit. . . . . . . 417

Der dritte Abschnitt.

Von der philosophischen Frőmmigkeit.

Das I. Hauptstŭck.

Von der Erkenntniß, Liebe und Furcht Gottes. . . . 422 Das II. Hauptstůck.

Von der Ehrfurcht, dem Vertrauen und der Gelassenheit gegen Gott. . . . . . . . . . . . 431 Das III. Hauptstůck.

Von dem Gebethe, der Danksagung und dem Gottesdienste. . . . . . . . . . . . . . . . 437

Der praktischen Weltweisheit Vierter Theil.

Die Staatslehre.

Einleitung zur Staatslehre. 445

Der erste Abschnitt.

Von der Haushaltungskunst.

Das I. Hauptstůck.

Von der Wohlfahrt des Ehestandes. . . . . . . . 447 
Das II. Hauptstůck.

Von der Kinderzucht. . . . . . . . . . . . 451

Das III. Hauptstůck.

Von Regierung des Hausgesindes und ganzen Hauses. 458

Der zweyte Abschnitt.

Von der Herrschsucht.

Das I. Hauptstůck.

Von kluger Einrichtung des gemeinen Wesens ůberhaupt. . . . . . . . . . . . . . 465

Das II. Hauptstůck.

Von der Sorgfalt der Regenten für die ihrer Bůrger Verstand und Erkenntniß. . . . . . . . . . . 470

Das III. Hauptstůck.

Von der Sorgfalt der Regenten fur die Tugend und Frómmigkeit ihrer Bürger. . . . . . . . . . . 476

Das IV. Hauptstúck.

Von der Sorgfalt eines Regenten, für das Leben, Vergnůgen und die Ehre seiner Bürger. . . . . . . . . 486

Das V. Hauptstůck.

Von Handhabung der Gerechtigkeit im gemeinen Wesen. . . . . . . . . . . . . . . . 495

Das VI. Hauptstúck.

Von guter Regierung des gemeinen Wesens. . . . 504

Anhang einiger Philosophischen Abhandlungen.

Vorbericht zur I. Abhandlung. . . . . . . . . 518

I. Abhandlung. oder philosophisches Gespråch, ůber die Frage: $\mathrm{Ob}$ mehr als ein unendliches Wesen seyn ko̊nne? . . . 519 II. Abhandlung.

Beweis, daß diese Welt unter allen die beste sey. . . 536 
III. Abhandlung.

Untersuchung der Frage: Wie sich ein Weltweiser, der von einer gôttlichen Offenbarung nichts wůßte, zufrieden stellen kônnte. . . . . . . . . . . . 560

IV. Abhandlung.

Philosophische Mutmaßungen von dem Aufenthalte der abgeschiedenen Seelen. . . . . . . . . . . . 569

V. Abhandlung.

Ob man die geoffenbarte Theologie in mathematischer Lehrart abhandeln kónne. . . . . . . . . 578

Register derer in beyden Theilen vorkommenden Sachen. 587 
